\title{
Educación intercultural y formación del profesorado ${ }^{1}$
}

\author{
Intercultural education and teacher training
}

Educação intercultural e formação de professores

María Isabel Lafuente Guantes $^{2}$
Instituto de Humanismo y Tradición Clásica - Universidad de León (España)
Grupo investigación HISULA

Recepción: 21/06/2016

Evaluación: 27/04/2017

Aceptación: 24/08/2017

Artículo de Investigación - Reflexión

DOI: https://doi.org/10.19053/01227238.7554

\section{RESUMEN}

Este trabajo realiza una reflexión, desde cooperación), finalidades (construcción de la Filosofía de la Educación, sobre la situación de la educación intercultural en la sociedad global, entendiendo que ni la filosofía ni el filósofo están exentos de intereses, y de atender a los giros: cognoscitivo y lingüístico. Se expone la situación actual de dicha forma de educación, y se enuncian y examinan los principios (diálogo crítico y sociedad de la identidad, construcción de racionalidad, construcción de personalidad), y acciones (prácticas sociales), esenciales para la formación del profesorado en esta modalidad educativa, así como la necesidad de incluir en ella la formación investigativa.

Palabras clave: acción social; estrategias educativas; ética; metodologías; valores.

$1 \quad$ El artículo se inscribe en el proyecto de investigación: "Formación de educadores en las Escuelas Normales Superiores". Convenio UPTC. 2010-2017. SGI. 2192 Dirección de Investigaciones Universidad Pedagógica y Tecnológica de Colombia. Lidera Dra. Diana Elvira Soto Arango.

$2 \quad M^{a}$ Isabel Lafuente es Catedrática de Filosofía (jubilada) y miembro de honor del Instituto de Estudios Humanísticos (Universidad de León (España)), al que porta sus investigaciones y publicaciones. Integrante del grupo de investigación HISULA de la Universidad Pedagógica y Tecnológica de Colombia. Email: milafg@unileon.es. 


\begin{abstract}
This work reflects, from the Philosophy of Education, on the situation of intercultural education in the global society. It is understood that neither philosophy nor the philosopher are exempt from interest, and have part in the turns: cognitive and linguistic. The current situation of this form of education is presented here along with the statement and examination of principles (critical dialogue and cooperative society), purposes (construction of identity, construction of rationality, construction of personality), and actions (social practices), essential for teacher training in this educational modality, as well as the need to include research training in it.
\end{abstract}

Keywords: social action; educational strategies; ethics; methodologies, values.

\section{RESUMO}

Este trabalho realiza uma reflexão, a partir da Filosofia da Educação, sobre a situação da educação intercultural na sociedade global, entendendo que nem a filosofia nem o filósofo estão isentos de interesses e de atender às viradas cognoscitiva e linguística. Expõe-se a situação atual desta forma de educação, e se enunciam e se examinam os princípios (diálogo crítico e sociedade da cooperação), finalidades (construção de identidade, construção de racionalidade, construção de personalidade), e ações (práticas sociais), essenciais para a formação docente nesta modalidade educativa, assim como a necessidade de incluir nela a formação investigativa.

Palavras-chave: ação social, estratégias educativas, ética, metodologias, valores.
Contextualización: Idioma Maya

$Q^{\prime}$ eqchi'

Contextualizador: Agustin Pelicó

Pérez

Ministerio de Educación de

Guatemala

\section{K'OSB'IL NA'LEB'}

Li k'anjel li wan sa' li perel hu a'in, naxtz'il rix chan ru wan ut chan ru nak'utman li tzolok chirix li k'iilawank sa' li junjunq chi nimla tzoleb'aal ut sa' li junjunq chi tenamit. Ab'anan tento xnawb'al naq li naxtz'il rix li tzolok a'in, junelik naraj xnawb'al k'a'ru nak'ulman chirix li na'leb' a'in, ut wan sa' xb'een rilb'al ma us li k'iila paay chi na'leb' ut li aatinob'aal li na'oksiman.

Sa' li perel hu a' in, naxk'ut chiruheb' li poyanam naq jwal us li tzolok chirix li k'iilawank, xb'aan naq sa' li junjung chi tenamit moko jun ta li aatinob'aal wan, k'iila paay b'an eb' li aatinob'aal li na'oksiman naq na'uxq li sum'aatinak. Jo'kan naq joq'e na'uxman li aatinak aajel ru xtz'ilb'al rix li k'a'ru nayeeman sa' li tzolok. Eb' li tenq' li nake'xk'e li najtil tenamit, aajel ru rilb'al chi us, xb'aan naq li xk'anjel a'an re xtenq'ankileb' li poyanam re naq ink'a' te'xmajewa rib' ut te'xloq'oni rib'.

Li wan sa' li perel hu a'in, taak'anjelak re xtenq'ankileb' li ixq ut li wing li yookeb' chi tzolok sa' li nimla tzoleb'aal, chi xtzolb'al li na'leb' chi rix li k'iilawank ut aajel ru aj wi' naq te'xtzol ut te'xkawresi rib' chirix li tz'ilok-ix.

$\mathbf{E b}^{\prime}$ li aatin tento xtzolb'al: li nab'aanuman sa' li komonil; k'iila xpaayil xk'utb'al li tzolok; $l i$ tiikil wank, li k'iila $x b^{\prime}$ ehil k'utuk ut eb' li loq'al. 


\section{INTRODUCCIÓN}

\section{Filosofía y metodología}

La educación intercultural requiere un planteamiento que se pregunte cuál es hoy la relación fundamental entre educación e interculturalidad. Este cometido, que es propio de una metodología filosófica, exige saber cómo entender la filosofía, su capacidad para introducirse en este campo y para poder aportar un conocimiento válido sobre su situación actual, así como sobre la orientación que prioritariamente hay que seguir.

La filosofía es una forma de conciencia, pero no la única; hay otras formas de conciencia, social, religiosa, política, histórica, etc., con las que la filosofía está en relación. A esta forma de ser propia de la filosofía la denomina G. Bueno implantación de la Filosofía. ${ }^{3}$ Este concepto comporta dos orientaciones: implantación gnóstica e implantación política ${ }^{4}$; en la implantación gnóstica la conciencia filosófica es:

“...conciencia desinteresada que ha sabido liberarse de toda pasión de todo partidismo, para consagrarse a la investigación pura de la "Verdad".

Esta idea, que corresponde a la concepción aristotélica según la cual la filosofía se ocupa de conocer la verdad, en última instancia de contemplar, permitió a Hegel afirmar que la filosofía era el grado supremo del espíritu absoluto, y que en él la Vorstellung (representación) religiosa se transforma en Verdad filosófica. Por el contrario, para una conciencia filosófica políticamente implantada:

"La estructura política [...] es una configuración práctica de la conciencia, en la cual se dan precisamente las conexiones entre las mismas regiones que el desarrollo cultural ha ido produciendo, y, por tanto, las ideas mismas que constituirán los temas de la especulación filosófica". ${ }^{6}$

Estas dos orientaciones de la filosofía, entre las que hay numerosas conexiones, suponen dos formas de relación del filósofo con la filosofía: conforme a la implantación gnóstica el filósofo solo tendrá interés en la búsqueda de la verdad, y según la implantación política el filósofo no puede estar separado de intereses propios (egocentrismo), y puede no estar separado de una ideología, pertenecer a un partido, ser ideólogo, e incluso fundador y líder de un partido, lo que es tanto como decir que el filósofo no es neutral, y puede estar comprometido políticamente. Que la filosofía se pueda concebir y realizar según estas dos nociones, implica que la respuesta a qué es filosofía no es simple e inmediata, pues exige

\footnotetext{
3 Gustavo Bueno Martínez, Ensayos Materialistas (Madrid: Taurus, 1972), 238-239.

4 Ibíd., 243-258.

5 Ibíd., 253.

6 Ibíd., 256.
} 
solucionar la inquietud general que suscita dicha oposición sobre qué se puede esperar cuando se inquiere a la filosofía cómo, y qué, hacer y pensar.

El problema inicial que plantea esta doble orientación de la filosofía es que en ninguna se niega que la filosofía sea práctica, pero en ambas se entiende la práctica de forma muy distinta. La concepción de la conciencia filosófica como conciencia gnóstica encuentra en la definición etimológica de filosofía: la filosofía como amor al saber y búsqueda de la verdad, la razón para sostener que ni la filosofía ni el filósofo pueden estar unidos a intereses particulares, y que la filosofía está por encima de cualquier realidad cultural y de cualquier interés concreto. Por el contrario, la implantación política sostiene que la conciencia filosófica surge en un contexto cultural, afirmación que no implica dejar de lado que la filosofía es una, ni que proporciona la verdad, pero sí que no está por encima de la realidad vital de los sujetos, de la sociedad en que viven, de la forma en que la viven, de la realidad política, económica, etc., por tanto, que no puede desligarse de intereses y conflictos sociales y culturales.

La conciencia gnóstica es propia de especialistas (de los artistas de la razón: casta sacerdotal o cuerpo de profesores ${ }^{7}$ ), la conciencia política es característica de la filosofía mundana que representa al filósofo: "como ciudadano, pero también como miembro de una clase social" ${ }^{\prime 8}$ por consiguiente, unido a intereses propios. Para G. Bueno, la filosofía gnóstica es "el error filosófico radical", ${ }^{9}$ mientras que la filosofía políticamente implantada es "la filosofía como verdad, como "conciencia verdadera". ${ }^{10}$ Afirmaciones que hacen más acuciante la respuesta a la pregunta sobre qué se puede esperar de la filosofía dada su implantación política, cómo puede proporcionar la verdad.

La respuesta a esta pregunta requiere comprender que la conexión fundamental entre ambas formas de conciencia tiene lugar porque, por una parte, la implantación gnóstica no puede prescindir de que el filósofo es un ciudadano, y aunque considere que la filosofía es propia de los individuos y se trasmite más por vía apostólica que política, no puede negar que siempre está unida a la práctica e influye en la sociedad, la política, la cultura, etc., y, por otra, desde la implantación política de la filosofía no se puede afirmar que la conciencia filosófica brota de forma espontánea, sino que, por el contrario, requiere una preparación académica suficiente, pues el sujeto tiene que tener capacidad para construir y reconstruir el conocimiento, por consiguiente, para saber sobre la verdad, es decir, que tiene que tener autonomía de pensamiento. Por tanto, la preparación filosófica, defendida por el gnosticismo, es necesaria para que pueda brotar la conciencia filosófica, pero esta, como sostiene la implantación política, no es independiente del contexto cultural, por consiguiente, del contexto social, político, económico, religioso, etc., en que se desarrolla la conciencia y la vida.

\footnotetext{
Ibíd., 262.

8 Ibíd.

9 Ibíd.

10 Ibíd., 263
} 
Las relaciones entre las dos orientaciones de la conciencia filosófica muestran que el cometido fundamental de la filosofía es establecer la conexión necesaria entre las ideas que permita la unidad de la razón, pero hay que tener en cuenta que si bien la filosofía es una, no hay una única filosofía, pues la filosofía, al cumplir su tarea propia, crea un orden entre las ideas que genera exclusiones. Por ello, es preciso atender a que en la práctica la filosofía siempre proporciona una interpretación, pero que existen una pluralidad de interpretaciones siempre en conflicto, del que siempre saldrá victoriosa la interpretación más fuerte, como entiende P. Ricoeur. ${ }^{11}$

La realidad de esta concepción es que la conexión filosófica de las ideas siempre se produce en un contexto, por tanto, también la verdad en la que consiste, lo que lleva a preguntar si objetivamente existe la verdad, o esta se diluye en el conflicto de las interpretaciones. La siguiente narración proporciona una respuesta negativa:

"Te contaré una historia. Es una historia judía. Un hombre va a ver a su rabino y le pregunta: "Si quiero encontrar la verdad, ¿es la solución morir?". "No" le dice el rabino. "Así, ila solución es la "vida?". "No" le vuelve a contestar el rabino. “¿Entonces, cuál es la solución?". A lo que el rabino contesta: “¿Y quién te ha dicho que hay una solución?".12

Ahora bien, la verdad sobre la que en este caso se pregunta, y sobre la que recae la respuesta anterior, es la verdad absoluta cuya respuesta no corresponde a la filosofía, ya que las condiciones a las que responde la verdad que logra nunca pueden ser absolutas, sino propias de un contexto, lo que no significa que no puedan ser válidas o aplicarse con verdad a otros.

Dada la innegable relación de la filosofía con la práctica, las metodologías fenomenológica y constructiva que vamos a seguir en esta exposición parten de que la acción es el origen de la interpretación, por consiguiente, de que somos lo que hacemos y lo que podemos hacer, por tanto, de que de la acción nace la necesidad y en ella se conoce la verdad, asumiendo que hay que contar con los dos giros que han tenido lugar a partir del siglo pasado, y los problemas que plantean: 1. Giro cognoscitivo. 2. Giro lingüístico.

El giro cognoscitivo cambió la dirección idealista que hizo del conocimiento la base de la acción, y entendió que la acción es base del conocimiento. El giro lingüístico, frente a la concepción clásica que hacía del lenguaje la forma de expresión del conocimiento, comporta dos pasos: $1^{0}$ la filosofía postmoderna afirmó que el lenguaje establece la realidad de las cosas, y su consecuencia fue que conocimiento y acción se redujeron a lenguaje; $2^{\underline{o}}$ la decadencia de dicha filosofía ha llevado a aceptar la necesidad del lenguaje, pero a sostener que si bien el

11 Ver: Paul Ricoeur, El conflicto de las interpretaciones (Madrid: F.C.E., 2015).

12 Mercè Ibarz, La palmera de blat (Barcelona: Quaderns Crema,1995), 135. 
lenguaje es el medio que permite constituir la realidad y el conocimiento de las cosas, ni el conocimiento y ni la acción se reducen a lenguaje.

\section{Formación del profesorado en educación intercultural: principios, finalidades (objetivos) y acciones}

Se considera que la educación intercultural es una modalidad educativa, pero hay que tener en cuenta que realmente la educación en general asumió desde finales del siglo pasado la condición de intercultural pese a las dificultades que planteaba esta noción, entre las que no son las menores atender a la pluralidad de perspectivas que comporta. Las principales son representadas en la tabla ${ }^{13} \mathrm{si}-$ guiente:

Tabla 1. Interculturalidad

\begin{tabular}{|l|l|l|}
\hline \multicolumn{3}{|c|}{ INTERCULTURALIDAD } \\
\hline Antropológica & Geopolitica & Sociológica \\
\hline Etnias & Emigración & Refugiados \\
\hline Razas & Migración & Asilados \\
\hline Tribus & & Minorías \\
\hline
\end{tabular}

Fuente: elaboración propia.

Estas perspectivas, a pesar de la diversidad de sus características diferenciales, se unifican como propias de grupos sociales marginales, para los que no se buscan soluciones a su situación como colectivos, sino que se disuelven en casos individuales de adaptación. En los últimos años la situación de estos colectivos ha generado preocupaciones de diversa índole:

1. Política: en relación a la gobernabilidad y participación democrática.

2. Social: en razón de la movilidad, la generación de violencia y agresividad.

3. Jurídico-política: en función de la aplicación de la legislación, de la responsabilidad-penal, y de la necesidad de nuevas legislaciones.

Estas preocupaciones, que se reflejan en la educación como falta de entendimiento, hacen preciso responder a la pregunta: ¿qué cambios se han producido en la educación para que en ella la interculturalidad sea un problema? El siglo pasado cifró la esperanza de igualdad, equidad y justicia en la economía del bienestar y en su principio: el crecimiento económico, para el que era fundamental tanto el progreso productivo como el progreso científico-tecnológico. En este siglo, el desarrollo de la sociedad global se ha unido a una economía neoliberal, que

13 La tabla es elaboración propia. Se ha realizado previa consideración de diversos textos, entre ellos: Ma Teresa Aguado, "La educación intercultural: concepto, paradigmas, realizaciones", en Carmen Jiménez Fernández, Lecturas de pedagogía diferencial, (Madrid, Dykinson, 1991), 89-104. Antonio Muñoz Sedano, "La educación intercultural, hoy", Didáctica, No. 7, (Madrid: Servicio de Publicaciones UCM (1995), 2017-2039, Jacques Delors, J. (coord.) Informe Unesco. La educación encierra un tesoro. (Madrid, Santillana, 1996). Antonio Bolívar, "Globalización e identidades:(des)territorialización de la cultura". Revista de Educación, número extraordinario (2001), 265-288. Martine Abdallah-Pretceille, La educación intercultural (Barcelona, Idea-Books, 2001). José Gimeno Sacristán, "El significado y la función de la educación en la sociedad y cultura globalizadas", Revista de Educación, número extraordinario (2001), 121-142. Axel Rojas y Elizabeth Castillo, "Multiculturalismo y políticas educativas en Colombia ¿interculturalizar la educación? Revista de educación y pedagogía, Vol. XIX. No. 48 (Medellín: Universidad de Antioquia (2009), 1124. 
ha dado lugar a la acumulación del capital en pocas manos y a la desaparición de las políticas de inversión, cuya consecuencia es una desigualdad progresiva, inseparable de la desaparición de la clase media y el empobrecimiento general de la población. Esta situación ha conducido a que la educación tenga que incorporar los medios que permitan promover la simetría de las relaciones humanas y sociales, para lo que se requiere dotar a los educandos de capacidades para promover igualdad (material y cultural) y armonía social, ${ }^{14}$ lo que supone asumir la tarea que la economía ha renunciado a cumplir.

Dada esta problemática, la formación del profesorado tiene que partir en la actualidad de que el objetivo de la educación es la formación de sujetos sociales, es decir, de sujetos capaces de atender a la diversidad de prácticas culturales y a su incardinación social sin menoscabo de que se logre la necesaria calidad profesional. ${ }^{15}$ Para ello, la educación tiene que capacitar a los sujetos para intervenir en la organización social, lo que requiere saber y poder establecer los elementos de una situación, de un conflicto o de un problema, y promover soluciones. La respuesta a la pregunta sobre cómo lograr estos objetivos tiene que partir de establecer los principios filosóficos que pueden guiar su cumplimientos, pues sin principios filosóficos no hay finalidad, sin principios y finalidad no hay acción, y sin acción no hay trasformación, por consiguiente es preciso establecer y contar con los siguientes elementos: principios + finalidad + acción (individual-social).

En la siguiente tabla se proponen los principios, finalidades (objetivos), y acciones indispensables para una formación del profesorado en educación intercultural, dada la problemática a la que hoy se enfrenta.

14 La educación hoy sigue las directrices del Informe PISA: Programme for International Student Assessment, que se ha convertido hoy en metro del nivel educativo de cada Estado y del nivel relativo entre los Estados. PISA no analiza los programas escolares nacionales, sino que revisa los conocimientos, las aptitudes y las competencias que son relevantes para el bienestar personal, social y económico (OECD 1999). Para ello no se mide el conocimiento escolar como tal, sino la capacidad de los estudiantes para poder entender y resolver problemas auténticos a partir de la aplicación de conocimientos de cada una de las áreas principales de PISA. Ver: Programa para la evaluación Internacional de los alumnos. Informe español. PISA 2012 (Madrid: Ministerio de Educación, Ciencia y Deporte, 2013).

15 Sobre los sujetos sociales, profesionales o trabajadores formados institucionalmente, recae la racionalización social, es decir, "la implantación de subsistemas de acción racional con arreglo a fines” por tanto, la institucionalización de empresas e institutos estatales, su organización, funcionamiento y gestión económica. Jürgen Habermas, Teoría de la acción comunicativa (Madrid: Taurus, 1987), Vol. I, 288. 
Tabla 2. Formación del profesorado ${ }^{16}$

\begin{tabular}{|c|c|c|}
\hline \multicolumn{3}{|c|}{ FORMACIÓN DEL PROFESORADO } \\
\hline PRINCIPIOS & FINALIDADES (objetivos) & ACCIONES \\
\hline $\begin{array}{l}\text { Diálogo crítico: } \\
\text { No dogmatismo } \\
\text { Validez } \\
\text { Verdad. }\end{array}$ & $\begin{array}{l}\text { Construcción de identidad: } \\
\text { contextos cognoscitivos y } \\
\text { prácticos. }\end{array}$ & $\begin{array}{l}\text { Prácticas educativo-socia- } \\
\text { les. }\end{array}$ \\
\hline $\begin{array}{l}\text { Sociedad de la coopera- } \\
\text { ción: } \\
\text { No coerción } \\
\text { Autonomía } \\
\text { Método. }\end{array}$ & $\begin{array}{l}\text { Construcción de racionali- } \\
\text { dad. } \\
\text { Construcción de personali- } \\
\text { dad. }\end{array}$ & Educación y acción social. \\
\hline
\end{tabular}

Fuente: elaboración propia.

\section{Contenido de los principios y finalidades (objetivos)}

Es evidente que conocer lo que comportan los principios, finalidades (objetivos) y acciones enunciados, requiere desarrollar su contenido. El diálogo crítico supone en la formación del profesorado asumir la eliminación de dogmatismos, es decir, huir de razones absolutas y de evidencias apodíctica. Sin embargo, hay que tener en cuenta que el diálogo crítico no puede llevar a instalar la duda como fundamento, ya que en este caso la duda se transforma en un estado y, como decía Ch. S. Peirce, la duda no es un estado pues no se duda a voluntad. Pero, también hay que atender a que Descartes instaló la duda como principio del método científico por considerar que la producción de conocimiento requiere una garantía moral, es decir, que el conocimiento comporta un problema práctico, y que su solución exige no partir de principios dogmáticos, de manera que solo aquello que al aplicar el método supere toda duda, todo supuesto adverso, puede ser considerado seguro tanto científica como social y humanamente. ${ }^{17}$ Por ello, rechazar el dogmatismo implica poder afirmar que existe la verdad objetiva, y que aunque no se puede olvidar que la verdad puede considerarse en dos niveles, pues en la capa objetual, se hace, y en la capa proposicional, se dice, la lógica material tiene capacidad para establecer la conexión entre lenguaje y objetos. ${ }^{18}$

16 La tabla es elaboración propia, sus bases son: el informe PISA (nota 13); las orientaciones del MEC para la Convergencia Europea (Ver: Carmen Alba Pastor (Coord.) Revista de Educación: Convergencia Europea y Universidad, No. 337, (Madrid: Ministerio de Educación y Ciencia (2005); las orientaciones de diversas universidades españolas para la elaboración de Guías Docentes en el marco de la convergencia con Europa; las obras de los autores de la Escuela de Frankfurt, sobre todo las de J. Habermas citadas en la bibliografía, y la obra de J. Piaget citada en la nota 22.

17 Descartes, que entiende que la diversidad de opiniones le dejan sin base en la qué apoyar el juicio, pero que la práctica en general y la práctica científica requieren proceder de forma segura, y saber qué opiniones son superfluas y cuáles no, se apoya en la moral para realizar la selección necesaria para construir un edificio seguro y cómodo, con el fin "de no permanecer irresoluto en mis acciones [...] y no dejar de vivir desde ese momento lo más felizmente que pudiera”. René Descartes, Discurso del Método (Madrid: Tecnos, 1987), 3a parte, 31. Es importante ver la formulación de las reglas de la moral en René Descartes, Correspondance. Descartes $a$ Élisabeth. (AT. IV, París: Vrin, 1976), 265-266, en dónde mantiene las reglas de la moral provisional al formular la moral definitiva.

18 El problema de la relación entre la lógica formal y la lógica material lo plantea este autor en: Gustavo Bueno Martínez, El cierre categorial (Oviedo: Pentalfa, 1992), vol. 1, 261-263. 
Hoy es preciso atender a aquellas afirmaciones, entre las que destaca la de Habermas, que sostienen que dado que la verdad tiene lugar socialmente hay que atener a la validez (de acciones, de expresiones, etc.), más que a la verdad. Esta tesis, que comporta los problemas propios de la relatividad de la verdad (psicologización, constricción, etc.) que socialmente generan falta de equidad, se puede precisar y resolver los problemas que envuelve si se entiende que el principio del conocimiento es la apariencia (fenómeno), que la verdad siempre exige una correlación de fenómenos producida de forma contextual, y que la medida de su universalidad es el contexto y su capacidad de reproducción. Fenomenológicamente suele recurrirse a un ejemplo que hoy han tomado las ciencias cognitivas como punto de partida: la percepción por los sujetos en un contexto, una estación (o un muelle) de dos fenómenos: una bandera y un tren (o un barco). Que el tren se ponga en marcha no depende de que se mueva una bandera, sino de la coordinación entre el movimiento de la bandera por el jefe de estación y su percepción por el maquinista, por tanto, el movimiento de la bandera es la señal, realizada por la persona autorizada, que el maquinista tiene que esperar para poner en marcha el tren. Es decir, la verdad, el movimiento del tren, no resulta de un poder mágico de forma que el movimiento de la bandera haga arrancar el tren, sino de que la persona apropiada haga la señal necesaria para que el maquinista lo ponga en marcha. Entender la verdad de esta forma la muestra como equivalente a validez. La relatividad de la verdad, así como su consecuencia inmediata la falta de equidad, solo resultan cuando la convención en que concluye el orden cognoscitivo, la señal, no se sustenta en condiciones morales aceptables que la hagan válida, sino que se instala dogmáticamente por un poder, pues entonces se lesionan gravemente los intereses de la sociedad, de sus colectivos y miembros.

El diálogo crítico tiene como finalidad (objetivo) la construcción de identidades cuyos dos problemas fundamentales son: el poder hegemónico y la marginación, ambos inseparables de los conflictos que soporta la noción de sujeto, en la que necesariamente se apoya, cuando esta resulta un simple comodín, es decir, solo útil para referirse tanto a objetos como a sujetos, y de distintos niveles. Esto se puede percibir en la filosofía postmoderna, y en que cuando canta la muerte del sujeto se refiere tanto a la pérdida de identidad del individuo, transformado en un sujeto errante, en un nómada, que ha de luchar constantemente por lograrla, como a la pérdida de identidad de las sociedades, consecuencia de una movilidad social en aumento, y que ha aumentado con las emigraciones masivas provocadas por los acontecimiento bélicos internacionales

La solución al problema, que ya fue enunciada por H. Zemelman: ${ }^{19}$ la necesidad de rescatar al sujeto, como la lleva a cabo J. Habermas ${ }^{20}$ parte de aceptar que a priori no existe un mundo común, y que el mundo común hay que construirlo constantemente, lo que remite a la tesis de Sartre del universal concreto, es decir,

19 Ver: Hugo Zemelman, Voluntad de conocer: el sujeto y su pensamiento en el paradigma crítico (Barcelona: Anthropos, 2005$), 56$ y ss.

20 Jürgen Habermas, Teoría de la acción comunicativa (Madrid: Taurus, 1987), Vol. I, 119. 
a que la identidad se construye en la situación. ${ }^{21}$ Los medios del diálogo que hoy se consideran fundamentales para construir la identidad tanto individual como social son las tradiciones, que comprenden: costumbres, mitos, imaginarios sociales, comunitarios, etc. En las tradiciones, según muestra Habermas, ${ }^{22}$ se apoya la construcción de argumentos, pues de ella se extraen las razones para justificar algo como verdad y dar lugar a argumentaciones, entendidas como los razonamientos en que se explicita el argumento, cuyas características lógicas son: consistencia (no-contradicción) y coherencia (referencia a los hechos).

En tanto la argumentación implica un discurso con finalidad persuasiva, exige validez práctica (moral) y remite a una base ética, entendida esta disciplina de forma amplia como reflexión sobre la conducta humana. La necesidad de que los principios de una argumentación sean éticos radica en que siempre se consolidan en valores y estos por ser principios de acción afectan directamente a los intereses. Ahora bien, los principios éticos dependen de la ética que se sustente, siendo las dos orientaciones fundamentales: la ética irracionalista, ética de la subjetividad cuyos valores básicos responden a la oposición egoísmo/altruismo; y la ética racionalista, ética social y objetiva cuyos valores responden al bien común. Aunque, ciertamente hay una pluralidad de formas éticas (formales, materiales, consecuencialistas, etc.), por lo que en la acción los valores nunca suelen darse de forma pura, siempre existe una jerarquía y, por tanto, un valor hegemónico, de manera que toda argumentación tiene que partir de inquirir:

1. ¿qué valores (principios de acción) seguir?

2. ¿qué validación, es decir, ratificación, pueden lograr?

En cuanto los valores, como la acción, no son independientes del conocimiento, las preguntas anteriores tienen su complemento en las siguientes:

3. ¿qué puedo hacer con lo que sé?

4. ¿qué puedo aportar con lo que hago?

5. ¿qué resultados produce comunitaria, social y humanamente?

La pluralidad de éticas, así como las interrogantes sobre los valores que abren, exigen saber qué ética es capaz de proporcionar los principios que permitan realizar una argumentación válida. En este sentido la ética de la argumentación, o ética falibilista, aporta un principio fundamental: cuando se produce una argumentación contra-fáctica es preciso variar los principios. Evidentemente los principios éticos no se pueden variar siempre, ni de cualquier manera; ahora bien, es necesario variarlos cuando los argumentos usados en la argumentación contradicen los hechos, pero, ¿cómo proceder para variarlos? Es evidente que no hay una fórmula para crear principios de argumentación válidos, pero las condiciones que permiten saber cómo buscarlos tienen que contar con los principios de las filosofías de la sospecha en sentido amplio, es decir, no solo con

21 La situación es para Sartre la condición negativa de la libertad empírica y práctica. Cfr.: Jean-Paul Sartre, L’Être et le Néant, (Paris: Gallimard, 1943), 566. Para Habermas el éxito de la acción teleológica y el consenso: "constituyen los criterios del buen o mal suceso en los esfuerzos por dominar una situación. Una situación representa un fragmento de la vida delimitado en vistas de un tema. Un tema surge en relación con los intereses y fines de acción." Jürgen Habermas, Teoría de la acción comunicativa. (Madrid: Taurus, 1987), Vol. II, 181.

22 Ibíd., 119-121. 
los principios a los que responde la ocultación y el engaño, sino también con aquellos de los que depende el auto-engaño, entendido como la mala-fe de Sartre. Estas condiciones, que prolongan la necesaria duda inicial en un proceso fenomenológico ( $d u d a \Rightarrow$ proceso fenomenológico), no pueden proporcionar de forma inmediata resultados satisfactorios, sino tan solo iniciar el proceso que permita que se sedimenten.

El mundo intercultural exige ayuda mutua entre países, comunidades, etc., es decir, solidaridad, que es el valor más importante de la ética irracionalista; pero la solidaridad, en la ética irracionalista, es aleatoria por completo, pues, según se muestra en la filosofía de Schopenhauer, ni se sabe por qué, ni cuándo, ni dónde aflora. Cuando se habla de solidaridad lo que se ensalza y alaba es la acción por su carácter totalmente voluntario, libre y desprendido, pero la eficiencia y equidad social que requiere la sociedad global no pueden cumplirse si no se fomentan prioritariamente los valores propios de la ética racionalista, es decir, valores que propicien soluciones sociales a los problemas, de forma que lo que se llama solidaridad en este caso obedece a recursos y medios establecidos dentro del orden legalmente constituido.

Si bien el diálogo crítico tiene como objetivo principal el entendimiento, en cuanto este comporta la construcción de un mundo común que permita la construcción de identidades, es preciso señalar que aunque la base del diálogo sea la elección de los principios éticos (principios de acción, es decir, valores) que los sujetos realizan, esto no supone que se prescinda del conocimiento, ya que, por el contrario, es el requisito indispensable para saber y expresar la orientación y aportaciones que la elección propicia. En un artículo no es posible exponer la noción de conocimiento por extenso, pero sí indicar sus términos y la relación entre ellos. En este sentido, hay que partir de que si bien el conocimiento no se puede reducir al lenguaje, como inicialmente mantuvo el giro lingüístico, lo implica necesariamente, tanto en sus dos términos previos: principios teóricos e información, como en su término final: formulación del concepto, que permite su normalización y da lugar a su uso. Tampoco el giro cognoscitivo, que hoy ya no es independiente del giro lingüístico, al sostener la prioridad de la acción, resta importancia al conocimiento ya que, por el contrario, entiende que en él reside la posibilidad de innovación, dado que solo en cuanto el concepto es incorporado a las prácticas se pueden percibir sus limitaciones y dar lugar a que la acción promueva el regressus a la idea, cuya captación lleva en el progressus a buscar la forma en que es preciso variar los principios que permitan innovar las prácticas.

Lo primero que resalta al preocuparse por el tema de la identidad, es que actualmente la construcción de identidad resulta un término genérico que se aplica tanto a la construcción de la identidad individual, nacional, a la de comunidades, o a la de un estado entre estados, y que se exige llegar tanto a construir modelos (la nación de naciones, la nación de comunidades), como a dar cuenta de los problemas que supone la construcción de ciudadanía. En tanto los principios éticos y cognoscitivos que permiten dicha construcción se aplican a las prácticas en el contexto vital cuya característica es la pluralidad de contenidos y sentidos, 
la construcción de la identidad afecta muy mucho a las competencias que se exigen para la formación del profesorado en educación intercultural, pues estas ya no pueden ser solo metodológicas y cognoscitivas, sino también, éticas, aptitudinales y emocionales.

El otro principio, del que dispone la educación para formar en la construcción de la identidad es la sociedad de la cooperación, noción, que fue elaborada por J. Piaget. ${ }^{23}$ Para este autor, la construcción de la identidad de los individuos no es independiente de la construcción de identidad social, y ambas consisten es un proceso que va de una sociedad y una moral carente de independencia, de una sociedad coercitiva y autoritaria y de una moral heterónoma, a una sociedad cooperativa y a una moral autónoma. La construcción de identidad y la socialización son procesos de equilibración sociales, no biológicos, en los que la buena construcción de identidad, social e individual, la buena socialización, tiene lugar cuando se logra eliminar toda forma y principio dogmático, impositivo, en favor de conductas autónomas. Ahora bien, de la socialización como proceso educativo- social, y aunque no se limite a la edad o estatura del ser humano, no pueden eliminarse de raíz ni las imposiciones ni los dogmas, ya que, por el contrario, son necesarios educativamente para producir la autonomía del sujeto, de manera que la educación reproduce las formas de la sociedad de la dependencia y la coerción, en grados y aspectos, de las que la relación individuo-sociedad y la de sociedad-sociedades tiene que ir desprendiéndose hasta lograr el nivel de la cooperación. Las etapas que sigue el proceso educativo de socialización son las siguientes:

1a Etapa: El sujeto depende del entorno social.

2a Etapa: La relación individuo sociedad es propia de la sociedad autoritaria tradicional, que se caracteriza por la coerción sobre el individuo, que ha de supeditar su acción y pensamiento a las normas establecidas por la autoridad constituida.

3 ${ }^{\text {a }}$ Etapa: Su característica es la cooperación en que las relaciones sociales se definen por la igualdad y reciprocidad.

La buena socialización, cuyo correlato es el proceso de equilibración en que el sujeto construye su conocimiento, conducta y capacidad de acción, por tanto su identidad, implica pasar de una moral heterónoma, a la autonomía moral y a la objetividad, y supone poder construir el objeto no por referencia al yo (egocentrismo), ni atribuyendo a los otros sujetos acciones artificiales, sino por su relación con los otros objetos. En este mismo proceso, en que el sujeto construye la racionalidad, construye también su personalidad, lo que también tiene lugar en sociedad, por tanto, construye su ego en relación con los otros egos, lo que supone la interiorización de la experiencia, y concluye en la constitución de la realidad objetiva.

23 La exposición que se realiza de esta noción sigue el siguiente texto: Jean Piaget. J. "Lindividualité en histoire: l’individu et la formation de la raison", en: L'individualité: troisième semaine internationale de synthèse [organisée par le] Centre international de synthèse / Maurice Caullery... [et al.]. (París: F. Alcan, 1933). sobre todo 70-74 y 90-91. 
Para Piaget no existe separación entre los polos individual y social, de manera que el proceso de construcción individual del conocimiento, de la identidad, de la personalidad, etc., no es independiente de las condiciones sociales, ya que siempre supone la interiorización de las propias acciones exteriores, e implica la interiorización de la exterioridad social, y, en ambos casos, no solo de lo que es de hecho, sino también, y sobre todo del ideal que comportan, lo que supone que la sociedad y la ciencia no vayan contra los intereses de los sujetos, sino que los potencie y respeten su autonomía.

Ahora bien, la sociedad de la cooperación solo propone un método, no creencias o normas, por lo que dado que su principio fundamental es que la racionalidad no es espontánea, la finalidad educativa que promueve, que es la transformación de la inteligencia sensorio-motriz en inteligencia reflexiva, tiene que incluir necesariamente conciencia del fracaso, percepción de las limitaciones, así como en qué residen, en función del ideal propuesto por el mismo método. La capacidad para adquirir conciencia de los límites que exige la inteligencia reflexiva, la propia de la sociedad libre, que es la única en que puede desarrollarse y en la que puede tener lugar la autonomía de individuos, ha de comportar capacidad para poder proponer un nuevo método que permita alcanzar el ideal.

Establecer las relaciones entre los dos giros, cognoscitivo y lingüístico, tiene que tener en cuenta que aparecen de forma secuencial, por tanto, que el movimiento que hizo de la acción el principio del conocimiento (del que forma parte la obra de Piaget) se prolongó en el que llevó al lenguaje a ser la forma de constitución de la realidad, lo que tuvo lugar a partir de la tesis de los actos de habla de J. Austin, ${ }^{24}$ y este en el desarrollo de la pragmática del lenguaje realizado por Habermas, ${ }^{25}$ en la que ya el lenguaje aparece como medio para la acción. Pero, ya desde su inicio, existen en ambos giros tesis que ponen de relieve las relaciones lenguaje-acción-conocimiento, así Austin, con apoyo en la relación lenguaje-contexto, consideró que enunciar algo en el contexto apropiado implica no solo decir algo, sino hacerlo, ${ }^{26} \mathrm{y}$, con el fin de poder resolver los problemas de significado, realización, verdad, efectuación, etc., que para el conocimiento resultan de la relación lenguaje-contexto, distinguió tres actos de habla: locucionario, ilocucionario, perlocucionario. ${ }^{27}$ El primero de ellos (locucionario), corresponde al contenido proposicional propio de las oraciones asertóricas de la dimensión cognitiva del lenguaje, en las que el acto de habla supone decir algo con significado verdadero o falso según su sentido y referencia. El acto de habla ilocucionario, que no tiene forma proposicional propia, expresa la fuerza o poder que corresponde al acto locucionario según el uso, como tiene lugar en la oración realizativa, ejemplo: ¡hola! La meta ilocucionaria no es que el oyente conozca lo que el hablante piensa, sino que llegue a la convicción de qué es aquello de lo que está persuadido, lo

24 Esta tesis se desarrolla inicialmente en: John Langshaw Austin, Cómo hacer cosas con palabras. (Barcelona: Paidós, 1981).

25 Jürgen Habermas, Pensamiento Postmetafísico (Madrid: Taurus, 1990), 126 y ss.

26 Cfr.: John Langshaw Austin, Cómo hacer cosas con palabras. (Barcelona: Paidós, 1981), 138. Como es sabido un acto locucionario se desglosa en tres actos: fonético (emisión de ruidos), fático (emisión de términos o palabras) y rético (sentido que se da, uso).

27 Ver: John Langshaw Austin, Cómo hacer cosas con palabras. (Barcelona: Paidós, 1981), 138-145. 
que supone que el oyente participe de la pretensión del hablante de que serán satisfechas las condiciones que hacen verdadera la oración afirmada.

El efecto perlocucionario, que caracteriza al tercer acto de habla, surge cuando el acto ilocucionario implica una función teleológica, es decir, una orientación de la que depende su influencia en el oyente, lo que supone una instrumentalización por intenciones contingentes, por ejemplo, iprometo que! Actualmente se considera en teoría de la comunicación que del efecto perlocucionario depende la aproximación de la acción estratégica y la acción instrumental, como cuando se entiende que las estrategias son acciones programadas, pues entonces la estrategia resulta ser "una elección que se realiza en consonancia con el proyecto", ${ }^{28} \mathrm{y}$ que se aproxima a la táctica en tanto ambas son medios para lograr un objetivo:

"Cuando hablamos de cómo lograr algo, cómo alcanzar un objetivo, estamos en el terreno de la estrategia y la táctica; entre ellas la diferencia es solo el nivel de acción y jerarquía". ${ }^{29}$

Pero, es posible diferenciar entre ellas porque la estrategia puede fundarse en valores compartidos, y cuando esto sucede se aproxima a la acción comunicativa, y no la acción instrumental.

Como toda ciencia, las Ciencias de la Educación no se reducen al lenguaje, pero no puede realizarse sin él porque incluyen en su desarrollo a los individuos, y la construcción del objeto solo puede tener lugar mediante la relación entre conocimiento y actividad subjetiva e intersubjetiva:

"Los signos y la ciencia están inextricablemente conectados, habida cuenta de que la ciencia, simultáneamente, ofrece a los hombres signos más fiables y expresa sus resultados en sistemas de signos." ${ }^{30}$

Según Ch. S. Morris, el lenguaje es un conjunto de signos interconectados, ${ }^{31}$ a cuyo estudio denomina semiótica, y semiosis al proceso en que algo es signo, cuya característica fundamental es que "algo toma en consideración algo mediatamente, es decir, a través de algo". ${ }^{32}$ Distingue cuatro mediadores, que son al propio tiempo términos y "propiedades relacionales que las cosas asumen al participar en el proceso funcional de semiosis" ${ }^{33}$ : signo, designatum, interpretante e intérprete. Algo es signo si un intérprete lo toma en consideración ante la presencia de otro algo; designatum es lo que se toma en consideración, y puede ser un objeto físico, cultural, concebible, un propósito, etc., es decir, algo determinado, o indefinido; las consideraciones de los agentes son los interpretantes siempre que sea evocado por algo que funciona

28 Pascale Weil. La comunicación global (Barcelona: Paidós, 1992), 197

29 Norma Macías, Diana Cardona. Comunicometodología. (México: Universidad Intercontinental, 2007), 120.

30 Charles Morris. Fundamentos de la teoría de los signos (Madrid: Paidós, 1971), 37.

31 Ibíd., 43-79.

32 Ibíd., 28.

33 Ibíd. 
como signo, y los agentes del proceso son los intérpretes, pero teniendo en cuenta que en el proceso se puede entender que el intérprete es un objeto, en tanto que mediatamente otro $\mathrm{u}$ otros sujetos lo toman en consideración para algo. De las relaciones entre los términos de la semiósis, Morris extrae tres dimensiones que permiten concebir la realidad del proceso, estas son: sintaxis, semántica y pragmática. La sintaxis se ocupa de las relaciones lógicas entre los signos, por ejemplo, un signo implica otro signo, siendo el signo el medio para poder comunicar algo. La semántica se ocupa de las relaciones entre signos y objetos, y se dice que el signo designa o denota (G. Frege: Sinn, Bedeutung), lo que remite tanto al designatum del signo, es decir, a la correlación entre el signo y objetos, como a saber si el signo tiene denotandum, es decir, si hace referencia a objetos físicos, o solo concebibles. La pragmática se ocupa de las relaciones entre el signo y los sujetos.

Para K. Bühler, el lenguaje es un órganon, por tanto, un sistema regido por normas que se especifican en el conocimiento de lo que el acto lingüístico comporta, y que responde a tres funciones por las que el fenómeno acústico se transforma en signo lingüístico: 1. Por la función representativa algo es signo por su referencia a objetos, y permite constituir un símbolo; 2. Algo es síntoma (indicio), por la función expresiva, es decir, por su dependencia del emisor, cuya interioridad expresa; 3. Algo es señal por la función apelativa, esto es por su apelación al oyente, cuya conducta externa o interna dirige. ${ }^{34}$ Estas funciones, como pone de relieve G. Bueno, dan lugar a una estructura intra-lingüística en tanto cada función liga a la otra a través de la tercera según grados y aspectos, de manera que el sujeto emisor (SE) se relaciona con el sujeto receptor (SR) mediando la relación de ambos a los objetos $(\mathrm{O}-\mathrm{O})$, en esquema: [SE (O-O) SR], lo que permite distinguir las relaciones lingüísticas de las extralingüísticas que son relaciones directas (S1, S2). ${ }^{35}$

En la tabla siguiente ${ }^{36}$ se representan las funciones lingüísticas de K. Bühler:

Tabla 3.

\begin{tabular}{|l|l|l|l|}
\hline $\begin{array}{l}\text { Funciones } \\
\text { lingüisticas (K. } \\
\text { Bühler) }\end{array}$ & Acto lingüístico & Pretensión de validez & Referencia ontológica \\
\hline $\begin{array}{l}\text { Representativa } \\
\text { (Asunto) }\end{array}$ & Verificativo & Verdad & Objetiva \\
\hline $\begin{array}{l}\text { Apelativa } \\
\text { (Oyente) }\end{array}$ & Regulativo & Exactitud & Social \\
\hline $\begin{array}{l}\text { Expresiva (Ha- } \\
\text { blante) }\end{array}$ & Expresivo & Veracidad & Subjetiva \\
\hline
\end{tabular}

Fuente: elaboración propia.

34 Cfr:: Karl Bühler, Teoría del lenguaje. (Madrid: Revista de Occidente, 1961), 48.

35 Cfr.: Gustavo Bueno Martínez, Estatuto Gnoseológico de las ciencias humanas. (Oviedo, 1976) Vol. 1, 364.

36 La tabla es de elaboración propia; su base es la obra K. Bühler citada en la nota 32, y la obra G. Bueno citada en la nota 33. 
En educación el uso de estrategias educativas es imprescindible, pero muchas veces se usan sin un diseño previo, mientras que hoy es preciso transmitir al alumno con claridad los principios y objetivos. Las más comunes: cognitivas, motivacionales y teleológicas, se pueden poner en relación con las funciones lingüísticas de K. Bühler, con su base, las dimensiones semióticas de Ch. Morris, y con los actos del lenguaje de la pragmática Austin, de forma que, a partir de entender el proceso comunicativo como una estructura de relaciones, se puede establecer la concomitancia y correspondencia entre las estrategias educativas y las formas básicas del proceso cognoscitivo-comunicativo:

1. Las estrategias cognitivas, que se preocupan de cómo transmitir conocimientos y de cómo llevar al alumno a lograr un conocimiento adecuado de manera que se enfrente a los temas de forma favorable, corresponden a la dimensión semántica de Morris, y a la función representativa de Bühler en la que la comunicación se centra en el asunto o tema (objeto) buscando cómo establecer su identidad de forma objetiva; pragmáticamente se centran en los actos locucionarios e ilocucionario. El objetivo de estas estrategias es constituir el objeto en relación al sujeto; la relación a que da lugar es simbólica, de manera que la identidad del objeto, en la relación sujeto-objeto, cumple la función de símbolo.

2. Las estrategias motivacionales se preocupan por favorecer el aprendizaje y el mejor desarrollo de la autonomía con base en necesidades, deseos o motivos, y requieren tener creencias e intenciones. Se centran en el sujeto receptor (oyente) que debe regular su conducta, conforme a las señales lingüísticamente constituidas, de manera que esta se desarrolle satisfactoriamente en el ámbito social. Por ello, se corresponden con la función apelativa de K. Bühler, y, en la dimensión pragmática, con los actos de habla perlocucionarios.

3. Las estrategias teleológicas que se centran en el sujeto emisor, y cuyo interés es lograr el mejor desarrollo del aprendizaje hasta su conclusión, se corresponden con la función expresiva de Bühler en cuanto sus manifestaciones constituyen las normas cuyo seguimiento se trata de favorecer, y los síntomas indicativos de los procedimientos a seguir en el proceso. En la dimensión pragmática los actos de habla que resultan privilegiados son el ilocucionario y su efecto perlocucionario.

4. Todas las estrategias se relacionan con la dimensión sintáctica de Morris cuando se entienden no en función de la docencia, sino en la relación del profesor o investigador con la disciplina como objeto de estudio.

\section{La acción social}

Solo se puede conocer en la acción si los principios logran cumplir su finalidad, es decir, si aquélla responde a ellos de forma consecuente. Por ello, si bien todo el esfuerzo educativo se ordena a lograr que los educandos alcancen conocimientos, capacidades y habilidades que les permitan tener un pensamiento claro, or- 
denado, bien estructurado y moralmente responsable, solo en la acción se puede saber sobre su efectividad. Es decir, la relación entre principios-finalidad-acción responde al mismo principio que la relación entre conocimiento y acción, lo que Habermas expresa en la forma siguiente: "sólo puedo saber si un hablante piensa o no lo que dice viendo si su actuación es consecuente, no por las razones que me da". En lo que respecta a la educación superior, la acción educativa se concreta en las prácticas educativas, y se inscribe en el marco general de la relación entre ciencia y tecnología, cuyas características son la universalidad de contenidos, la constitución de herramientas instrumentales, sean cognoscitivas o técnicas, y la pluralidad de aplicaciones, lo que las sitúa en el conjunto de las prácticas. De ahí que en educación haya que tener en cuenta que las prácticas siempre comportan negaciones y contradicciones, pero que de ellas, depende la constitución del sujeto trascendental como ego lógico e histórico, dado que la conciencia de las prácticas solo puede ser conciencia histórica. Y, en cuanto la educación no se separa de la acción social, es ineludible atender a que la contribución de la ciencia y la tecnología adquiere socialmente tres orientaciones fundamentales:

1. El desarrollo del potencial autóctono.

2. La aplicación contextual del conocimiento, así como de técnicas y tecnologías.

3. La representación formal del avance e innovación lograda (congresos, foros, movilidad del profesorado).

La educación intercultural no se puede separar de las prácticas sociales, ya que pretende incardinar y armonizar en ellas diversidad de prácticas culturales (individuales y comunitarias), por lo que es preciso tener claro qué persigue la acción social, y en este sentido Max Weber es un punto de partida ineludible para saber a qué responde la conducta humana en contextos sociales, por tanto, de la acción de un sujeto ante la actitud de otro. En la consideración que Weber hace de la acción, y que desemboca en su clasificación según tipos (acción ligada a fines, a valores, a formas tradicionales, a afectos) o según criterios (eficacia y verdad), se apoya la clasificación de la acción de Habermas en:

1. Acción instrumental: acción que en principio no es social, pero puede serlo, y que se caracteriza por la búsqueda de éxito y el uso de reglas técnicas.

2. Acción estratégica, que es propiamente acción social, se rige por la búsqueda de éxito y se apoya en la elección de normas.

3. Acción comunicativa: acción social orientada al entendimiento, que promueve mediante la armonización de planes y se apoya en aquellos valores que son comunes a distintos sectores.

La finalidad de la acción social es según Habermas la búsqueda de consenso, noción sobre la que desde su inicio no hubo acuerdo entre los investigadores, sino posturas divergentes. Entre ellas la de J. Piaget, que entendió que el consenso comportaba una imposición externa de algo común mediante una representación simbólica, por tanto, que se llegaba a establecer como ley un producto fruto de la normatividad y la heteronomía. Por lo que, frente a la noción de consenso, 
promovió la necesidad de acuerdo moral, resultado de la unidad interna de perspectivas con apoyo en la autonomía de los sujetos.

En la sociedad global e intercultural, que es una sociedad altamente conflictiva, se considera que la solución a los conflictos reside en lograr un consenso, y que el medio es el diálogo, pero el proceso y sus resultado responden a las características del consenso que Piaget ponía de relieve: ser la unidad de las normas de acción que el poder político-económico está dispuesto a aceptar (moral heterónoma), y que a veces llegan a formularse en leyes. De ahí, que de esta forma la sociedad global no pueda lograr desarrollar una moral autónoma, ya que esta requiere que los sujetos, sin perder su condición egocéntrica, es decir, sus intereses propios, puedan construir su identidad ateniéndose y respetando el interés social, sino solo dar lugar a una moral heterónoma, solidaria de normas de acción impositivas y fijas que no favorecen la armonía social, sino la satisfacción de los intereses del poder.

Para Habermas, que en la sociedad global solo prosperen condiciones impositivas, depende tanto de que los sujetos sociales no han alcanzado una ilustración suficiente, como de que cuando algunos la alcanzan, se rechaza la ilustración como el medio para participar en el diálogo social. El problema de la ilustración de los sujetos es también el que lleva a Piaget a considerar que la sociedad de la cooperación solo es propia de investigadores, pero, sin embargo, considera que sería deseable que sus principios fueran también propios de la sociedad en general. Institucionalmente la educación puede favorecer una mayor ilustración de los sujetos mediante cursos complementarios, pero el medio académico para lograrla es impulsar que los docentes realicen un doctorado, que es el grado máximo de la educación y supone, además de una mayor preparación teórica, la realización de una tesis doctoral que implica una serie de condiciones ineludibles: en primer lugar, requiere que el tema sea idóneo y aporte nuevos conocimientos; en segundo lugar, que sea actual, y que se base en una suficiente información histórica, por tanto, que aporte una buena base documental; en tercer lugar, que su metodología sea tanto descriptiva (método de recuperación) como constructiva (método constructivo).

Seguir uno u otro método enfrenta a los investigadores, por entender unos que el método de recuperación implica no partir de esquema alguno y buscar el origen, el grado 0 propugnado por los filólogos, lo que implica negar la posición actual del investigador, y otros que el método constructivo impone un esquema previo a la investigación y reduce a él la documentación. Por ello, es necesario aclarar que al poner de relieve la necesidad de que para realizar una investigación se usen ambos métodos no se niega la necesidad de partir de un esquema previo, pero sí la de buscar un grado 0, que siempre resulta mítico y ficticio, y supone afirmar que la garantía de la originalidad e idoneidad de la investigación depende tanto del esquema del que se parte como de la selección y uso de las fuentes de información, que es necesario que sean idóneas, suficientes y fidedignas. La importancia de las fuentes en una investigación, permite afirmar que de la correcta aplicación del método de recuperación depende que el esquema nece- 
sario para realizar la construcción del conocimiento (método de reconstrucción) muestre su consistencia y fortaleza, es decir, que se pueda dar cuenta de ella.

Ahora bien, en lo que afecta a la aportación de conocimiento y su valoración, es preciso que el desarrollo del esquema articule la idea que propone (que inicialmente se puede formular en forma de hipótesis), con la información en que se apoya (fuentes históricas, técnicas y prácticas históricas, actuales), dando lugar a una unidad arquitectónica y no solo a una unidad técnica. Por tanto, el esquema es una organización del conocimiento que tiene que apoyarse en las fuentes de información seleccionadas (las prácticas en que se basan y a las que han dado lugar, así como en las técnicas de las que depende su uso), pero sin que el esquema proponga y siga una idea, y sin que esta se explicite y articule con las fuentes y prácticas suficientes, la investigación se reducirá a una unidad técnica, mientras que cuando el esquema expone una idea cuyo desarrollo se relaciona y apoya en las fuentes de información necesarias, se constituye una unidad arquitectónica (esquema: idea+técnicas (prácticas), dando lugar a un concepto que tiene como correlato la verdad que la investigación establece como propia. De proceder en la investigación de esta forma, depende tanto la idoneidad como la innovación de la realidad de un contexto y de su conocimiento.

La realización de una tesis doctoral es el medio para formar profesorado con experiencia propia de lo que comporta científica, cultural, cognoscitiva y prácticamente, la construcción de un contexto en que se muestre y pruebe una verdad, y de la capacidad de investigación propia en el doctorado depende el progreso científico y cultural sólido, y con proyección universal de un país.

\section{CONCLUSIÓN}

La educación intercultural no puede limitarse actualmente a favorecer la adaptación de los sujetos, pues la condición de interculturalidad ya no es la propia de la diversidad educativa, de atender a unos pocos "diferentes" que hay que incorporar a una base homogénea, sino de la pluralidad cultural que caracteriza hoy a las sociedades, de manera que afirmar que la sociedad globalizada es intercultural supone atender a variaciones, ejemplo: que los educandos pueden ser extranjeros en el sentido más completo (política y culturalmente), pero también que pueden tener la nacionalidad del país y no su cultura, o no su cultura más general y tradicional, lo que hace necesario precisar la noción de minoría cultural, y saber cómo atenderlas. De ahí que su tarea principal sea conocer, aplicar y buscar los principios que permitan conseguir una percepción real de los problema educativos en la sociedad global, las finalidades (objetivos) que ha de hacer suyas y conseguir cumplir, así como los problemas que su acción encuentra y la orientación que ha de mantener. El desarrollo que se ha seguido de los tres términos que comporta la educación intercultural: principios, objetivos y problemas, permite concretar sus logros prospectivos en: 1 . Propiciar y promover la in- 
cardinación social de prácticas culturalmente diversas, para lo que es ineludible propiciar la constitución de un mundo común, cuya base intralingüística remite a la relación [SE (O-O) SR] señalada, ya que es muestra de que el sujeto emisor y el receptor se constituyen como tales en tanto participan de relaciones objetivas comunes, que máximamente, en cuanto resultan independientes de sus voluntades, remiten a una base ontológica; 2. Lograr que el educando alcance las capacidades, habilidades, y nivel de ilustración suficientes para poder intervenir en el proceso de constitución del orden socio-cultural y en el mejor desarrollo de las condiciones sociales y políticas.

El diálogo crítico y la sociedad de la cooperación son los principios ineludibles que, unidos al lenguaje, constituyen las herramientas educativas imprescindibles para cumplir con la finalidad de potenciar la capacidad de los sujetos para lograr la construcción de un objeto (por ejemplo, un modo de entender la relación entre prácticas culturales diversas) que, como símbolo, obtenga reconocimiento objetivo y social, así como para construir su autonomía cognoscitiva y moral, alcanzar la inteligencia reflexiva y, por tanto, para poder reconstruir su identidad en los variados contextos sociales. Para ello, se requiere una preparación ética que capacite a los educandos para saber elegir los principios rectores de su acción, los valores que mejor logren satisfacer las necesidades y deseos, individual y socialmente, y para que puedan ponerlos en práctica, ya que la verdad y eficacia de los principios educativos solo se conoce en la acción. Pero, también una preparación suficiente en teoría de la acción que permita saber cómo circunscribir un contexto y estructurarlo lingüística y cognoscitivamente, así como las condiciones para modificarlo y dar lugar a la creación de una convivencia más armoniosa.

\section{FUENTES}

Abdallah-Pretceille, Martine. La educación intercultural. Barcelona, Idea-Books, 2001.

Aguado, Maㅡ Teresa "La educación intercultural: concepto, paradigmas, realizaciones", en Carmen Jiménez Fernández. Lecturas de pedagogía diferencial, Madrid, Dykinson, 1991.

Alba Pastor, Carmen (Coord.). Revista de Educación: Convergencia Europea y Universidad, No. 337. Madrid: Ministerio de Educación y Ciencia, 2005.

Rojas Axel y Elizabeth Castillo. “Multiculturalismo y políticas educativas en Colombia ¿interculturalizar la educación? Revista de educación y pedagogía, Vol. XIX. No. 48. Medellín: Universidad de Antioquia, 2009.

Austin, John Langshaw. Cómo hacer cosas con palabras. Barcelona: Paidós, 1981.

Bolívar, Antonio. "Globalización e identidades: desterritorialización de la cultura". Revista de Educación, número extraordinario, 2001.

Bueno Martínez, Gustavo. Ensayos Materialistas. Madrid: Taurus, 1972.

Bueno Martínez, Gustavo. Estatuto Gnoseológico de las ciencias humanas. Oviedo, 1976.

Bueno Martínez, Gustavo. El cierre categorial. Oviedo: Pentalfa, 1992.

Bühler, Karl. Teoría del lenguaje. Madrid: Revista de Occidente, 1961. 
Delors, Jacques (coord.). Informe Unesco. La educación encierra un tesoro. Madrid, Santillana, 1996.

Descartes, René. Correspondance. Descartes a Élisabeth. AT. IV. París: Vrin, 1976.

Descartes, René. Discurso del Método. Madrid: Tecnos, 1987.

Gimeno Sacristán, José. "El significado y la función de la educación en la sociedad y cultura globalizadas". Revista de Educación, número extraordinario, 2001.

Habermas, Jürgen. Teoría de la acción comunicativa, Vol. II. Madrid: Taurus, 1981.

Habermas, Jürgen. Teoría de la acción comunicativa, Vol. I. Madrid: Taurus, 1987.

Habermas, Jürgen. Pensamiento Postmetafísico. Madrid: Taurus, 1990.

Ibarz, Mercè. La palmera de blat. Barcelona: Quaderns Crema, 1995.

Lafuente, Ma Isabel. Teoría y Metodología de la Historia de la Filosofía. León: Universidad de León, 1986.

Macías, Norma y Diana Cardona. Comunicometodología. México: Universidad Intercontinental, 2007.

Morris, Charles. Fundamentos de la teoría de los signos. Madrid: Paidós, 1971.

Muñoz Sedano, Antonio. "La educación intercultural, hoy", Didáctica, No. 7. Madrid: Servicio de Publicaciones UCM, 1995.

Piaget, Jean. "L'individualité en histoire: l'individu et la formation de la raison", en: L'individualité: troisième semaine internationale de synthèse [organisée par le] Centre international de synthèse / Maurice Caullery... [et al.]. París: F. Alcan, 1933.

Programa para la evaluación Internacional de los alumnos. Informe español. PISA 2012 Madrid:

Ministerio de Educación, Ciencia y Deporte, 2013.

Ricoeur, Paul. El conflicto de las interpretaciones. Madrid: F.C.E., 2015.

Zemelman, Hugo. Voluntad de conocer: el sujeto y su pensamiento en el paradigma crítico. Barcelona: Anthropos, 2005.

Weber, Max. Economía y Sociedad. México: F.C.E., 1964.

Weber, Max. Ensayos sobre metodología sociológica. Buenos Aires: Amorrortu, 1978.

Weil, Pascale. La comunicación global. Barcelona: Paidós, 1992.

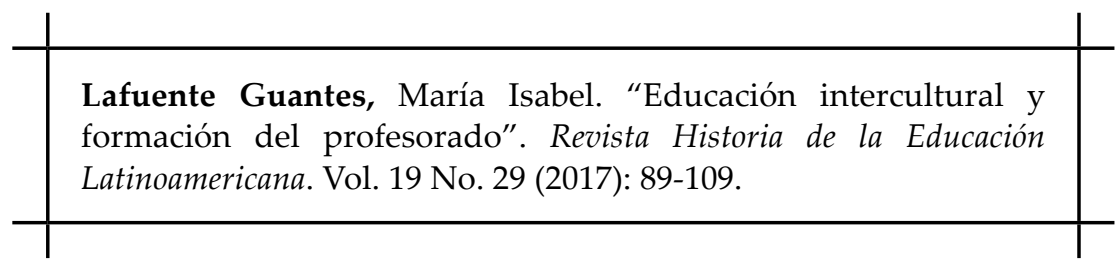

